July 2016, Volume 1, Issue 2 (36-40)

\title{
The Correlation between Serum Level of N-Terminal Pro-B-type Natriuretic Peptide and Gensini Score in Patients with Acute Coronary Syndrome
}

\author{
Mohammad Hassan Namazi ${ }^{1}$, Hossein Vakili ${ }^{1}$, Mahsa \\ Charkhkar ${ }^{1, *}$, Latif Gachkar ${ }^{2}$, Isa Khaheshi ${ }^{1}$ \\ ${ }^{1}$ Cardiovascular Research Center, Shahid Beheshti University of Medical Sciences, \\ Tehran, Iran \\ ${ }^{2}$ Infectious Diseases and Tropical Medicine Research Center, Shahid Beheshti \\ University of Medical Sciences, Tehran, Iran \\ * Corresponding author: Mahsa Charkhkar, Cardiovascular Research Center, Shahid \\ Beheshti University of Medical Sciences, Tehran, Iran. Tel: +98-2122083106, E-mail: \\ m.drcharkhkar@yahoo.com
}

DOI: $10.20286 /$ ijcp-010205

Submited: 06.01.2015

Accepted: 06.15.2015

\section{Keywords:}

pro-brain natriuretic peptide (76-1)

Gensini Score

Acute Coronary Syndrome Angiography

(C) 2016. International Journal of Cardiovascular Practice.

\begin{abstract}
Introduction: N-terminal pro-B-type natriuretic peptide (NT-proBNP) has emerged as an important biomarker for developing the diagnosis and prognosis of cardiovascular diseases, as several studies have shown that serum levels of NT-proBNP elevate in acute coronary syndrome (ACS) and coronary artery disease (CAD). We performed this study to find any possible correlation between serum levels of NT-proBNP and Gensini score in patients diagnosed with ACS.

Methods: In a cross-sectional study, 100 consecutive patients with ACS who were candidates of angiography were recruited and their serum levels of NT-proBNP, Gensini scores, lipid profiles and troponin I levels were measured.

Results: Sixty six male and 34 female patients with a mean age of 57.5 years, including 44 with unstable angina, 33 with ST-elevation myocardial infarction, and 23 with nonST-elevation myocardial infarction were enrolled. The mean serum NT-proBNP level and the Gensini score were $1987.16 \mathrm{pg} / \mathrm{mL}$ (17.9-8841) and 31.09 (6-92.5), respectively. The serum NT-proBNP levels and Gensini scores were significantly correlated with a Spearman correlation coefficient of 0.953 ( P < 0.001). Serum levels of NT-proBNP were not different in patients with single-vessel disease, 2-vessel disease and 3-vessel disease $(\mathrm{P}=0.257)$. NT-Pro-BNP levels were also correlated positively with troponin I levels (correlation coefficient $=0.779$ ) and negatively with left ventricular ejection fraction (correlation coefficient $=-0.55)$. Smoker patients had higher NT-proBNP levels $(\mathrm{P}=$ 0.047). Neither Gensini scores nor NT-Pro-BNP levels had significant correlation with lipid profile or blood sugar.

Conclusions: NT-proBNP is directly correlated with Gensini score in patients with ACS and might be used as an important marker for risk stratification in those patients.
\end{abstract}

\section{INTRODUCTION}

During recent years, new cardiac biomarkers have been explored as useful tools for diagnosis and risk stratification in patients with cardiovascular diseases including acute coronary syndrome (ACS) and coronary artery disease (CAD). One of the biomarkers that have been studied and shown promise in clinical practice is $\mathrm{N}$-terminal pro-B-type natriuretic peptide (NT-proBNP). BNP is synthesized as a 108 -aminoacid-long prohormone termed proBNP and secreted mainly from cardiac atrial and ventricular myocardium in response to increases in wall stress or inflammation
[1-4]. After secretion, this propeptide is divided into its biologically active BNP and the NT-proBNP.

Several studies have shown that serum levels of NT-proBNP elevate in a variety of functional and structural cardiac abnormalities, especially ACS and CAD [4-11]; therefore, NT-proBNP has emerged as an important biomarker for developing diagnosis and prognosis for cardiovascular diseases [12-14]. Some studies have reported the beneficial effects of NT-proBNP as a prognostic marker for predicting CAD severity based on angiographic findings $[10,15-18]$ as well as infarct size and myocardial function after myocardial infarction (MI) $[11,19,20]$. Meanwhile, other studies have 
suggested the predictive role of this peptide for assessing long-term mortality of patients with CAD [21-23]. Providing the establishment of NT-proBNP as an approved biomarker for risk stratification and predicting CAD severity in patients with ACS, measurement of this peptide as a non-invasive rapid and simple method can replace other invasive and costly procedures.

Based on these evidences, we performed this study to evaluate whether serum level of NT-proBNP is an appropriate predictor of CAD severity in patients with ACS. To achieve this goal, we tried to find any possible correlation between serum levels of NT-proBNP and Gensini scores in patients diagnosed with ACS.

\section{METHODS}

In a cross-sectional study, 100 consecutive patients, admitted in CCU of Shahid Modarres Hospital (a university hospital affiliated to Shahid Beheshti University of Medical Sciences in Tehran, Iran) in 2012 with diagnosis of ACS, were recruited. They included patients with unstable angina (UA), ST-elevation MI (STEMI), and non-ST-elevation MI (NSTEMI). Patients with ACS who were candidates of angiography were offered to participate in the study and in case of consent, a questionnaire was filled for each of them comprising their basic medical and demographic information. Twenty four hours after patients' last episode of chest pain, $5 \mathrm{~mL}$ of their venous blood was taken and their serum levels of NT-proBNP, troponin-I and creatinine, low-density lipoprotein (LDL), high-density lipoprotein (HDL), cholesterol, triglyceride (TG) and blood sugar were measured. Levels of NT-proBNP were measured by Enhanced Chemi luminescence (ECL) using Pro-BNP kit (Roche, Germany).

Patients underwent angiography by expert attending physicians. According to the angiograms, patients were divided into patients with single-vessel disease (SVD), 2-vessel disease (2VD), 3-vessel disease (3VD) and patients with isolated or concomitant left main artery (LM) involvement. The Gensini score was calculated for each patient from the coronary arteriogram by assigning a severity score to each coronary stenosis, according to the degree of luminal narrowing and its geographic importance. Reduction in the lumen diameter, as well as the roentgenographic appearance of concentric lesions and eccentric plaques were evaluated (reductions of $25 \%, 50 \%, 75 \%, 90 \%, 99 \%$, and complete occlusion were given Gensini scores of 1, 2, 4, 8, 16, and 32, respectively). Each principal vascular segment was assigned a multiplier in accordance with the functional significance of the myocardial area supplied by that segment: the left main coronary artery $\times 5$; the proximal segment of left anterior descending coronary artery $(\mathrm{LAD}) \times 2.5$; the proximal segment of the circumflex artery $\times 2.5$; the mid-segment of the $\mathrm{LAD} \times 1.5$; the right coronary artery, the distal segment of the $\mathrm{LAD}$, the posterolateral artery and the obtuse marginal artery $\times 1$; and others $\times 0.5[24,25]$. Angiograms were read by two independent readers blinded to patients' data and then averaged.

The exclusion criteria were creatinine $>1.5 \mathrm{mg} / \mathrm{dL}$, fever, body mass index $>30$, left ventricular ejection fraction $(\mathrm{EF})<40 \%$, age $>75$ years, and sever hepatic or pulmonary diseases. We used SPSS software version 15 for data anal- ysis. Quantitative variables are presented as mean. T-test and ANOVA were used for comparing two or multiple variables. To find any possible correlation of Gensini scores and serum levels of NT-proBNP with other variables, Pearson's and Spearman's correlation tests were used. A P value of $<$ 0.05 was considered as statistically significant.

The study protocol was approved by the Ethics Committee of Shahid Beheshti University of Medical Sciences. A written informed consent was obtained from each participant according to the Declaration of Helsinki.

\section{RESULTS}

Among 100 patients enrolled in the study, 66 were male and 34 were female. The mean age of the participants was $57.5 \pm$ 19.6 years; 44 had UA, 33 had STEMI and 23 had NSTEMI. Regarding their EF, $46 \%$ had EF of $60 \%$ or higher, $17 \%$ had EF of $55-60 \%, 36 \%$ had EF of $50-55 \%$ and one patient had an EF of $45-50 \%$. Fifty four patients were smokers. Laboratory and clinical results of the patients are shown in Table 1. The mean serum levels of troponin I and NT-proBNP and the mean Gensini score were $11.3 \mu \mathrm{g} / \mathrm{L}$ (range: $<0.05$ to 53), $1987.16 \mathrm{pg} / \mathrm{mL}$ (range: 17.9-8841), and 31.09 (range: 6-92.5), respectively. Angiography showed that $19 \%$ of the patients had SVD, $48 \%$ had 2VD, 27\% had 3VD and the other $6 \%$ had isolated or concomitant LM involvement. Of the patients, $79 \%$ had isolated or concomitant $\mathrm{LAD}$ involvement and $\mathrm{LAD}$ was not found in the remaining $21 \%$ of the patients.

\begin{tabular}{|lc|}
\hline \multicolumn{2}{|l|}{ Table 1: Laboratory and Clinical Results of the Patients } \\
Variable & Result \\
Creatinine (mg/dL) & $1.09 \pm 0.1$ \\
Blood sugar (mg/dL) & $182.7 \pm 83.8$ \\
LDL (mg/dL) & $115.8 \pm 21.8$ \\
Triglyceride (mg/dL) & $321.8 \pm 76.9$ \\
Cholesterol (mg/dL) & $277.2 \pm 58.0$ \\
HDL $(\mathbf{m g} / \mathbf{d L})$ & $44.03 \pm 7.7$ \\
Systolic blood pressure $(\mathbf{m m H g})$ & $140.0 \pm 16.2$ \\
Diastolic blood pressure $(\mathbf{m m H g})$ & $84.1 \pm 9.3$ \\
\hline
\end{tabular}

Data in table are presented as Mean \pm SD.

LDL: Low-density lipoprotein; HDL: High-density lipoprotein

We tried to find any possible correlation between the serum level of NT-proBNP and Gensini score in our patients. Using Spearman's correlation test, the correlation coefficient was $0.953(\mathrm{P}<0.001)$, which showed a significant direct correlation between the two variables. The correlation was significant in both genders, as the Spearman's coefficients were 0.977 and 0.862 in males and females, respectively $(\mathrm{P}<0.001$ in both). Fig $1-3$ depict the correlation between serum levels of NT-proBNP and Gensini score in all the patients and each gender. Additionally, the correlation was significant in all three groups of patients with ACS (Table 2). 


\begin{tabular}{|lcc|}
\hline Table 2: The Correlation between Serum Levels of NT-proBNP and Gensini Scores in Three Subgroups of Patients with ACS \\
Group & $\begin{array}{l}\text { Pearson's correlation coefficient } \\
\text { P value }\end{array}$ & $<0.001$ \\
STEMI & 0.80 & $<0.001$ \\
NSTEMI & 0.96 & $<0.001$ \\
\hline
\end{tabular}

UA: unstable angina; STEMI: ST elevation myocardial infarction; NSTEMI: non-ST elevation myocardial infarction

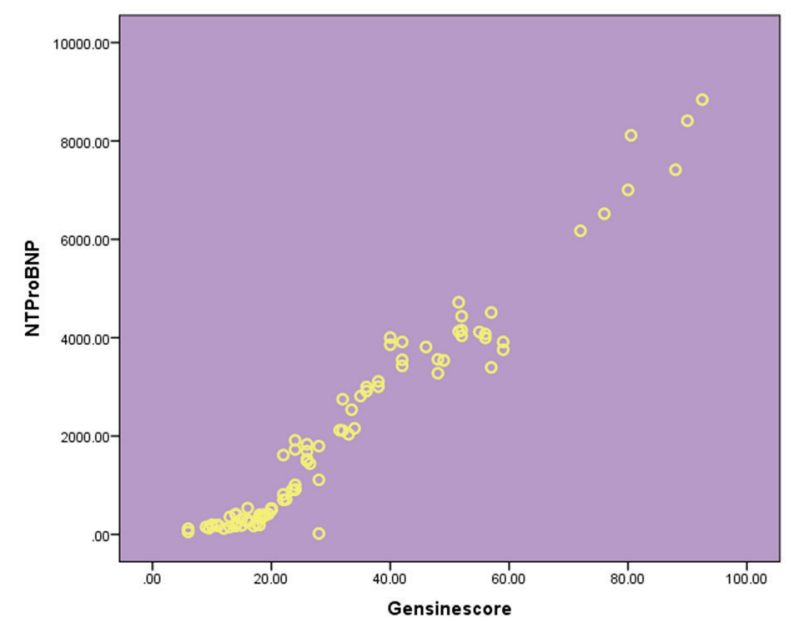

Figure 1: Correlation between Serum Levels of NT-proBNP and Gensini Scores in Patients

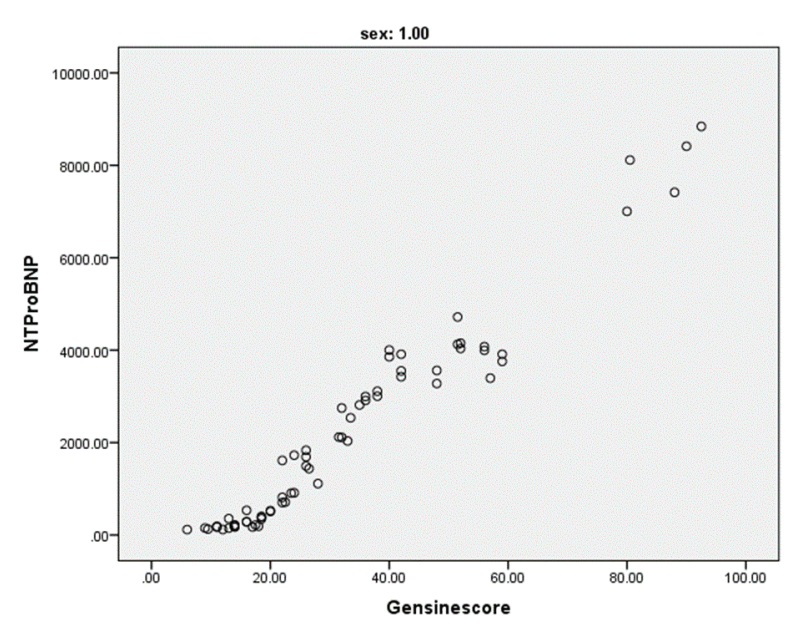

Figure 2: Correlation between Serum Levels of NT-proBNP and Gensini Scores in Males

ANOVA showed no significant difference between serum levels of NT-proBNP among the four groups of patients with SVD, 2VD, 3VD and patients with isolated or concomitant LM involvement $(P=0.257)$. Regarding the serum levels of NT-proBNP, there was also no significant difference between patients with and without LAD involvement $(P=0.294)$. However, the difference was significant comparing patients with UA, STEMI and NSTEMI $(\mathrm{P}<0.001)$.

In this study, patients with positive troponin I had higher NT-proBNP levels $(\mathrm{P}<0.001)$ and the correlation coefficient between them was 0.779 (Fig 4). There was also a significant indirect correlation between serum level of NT-PRO-BNP and $\mathrm{EF}$ with a correlation coefficient of $-0.55(\mathrm{P}=0.001)$.

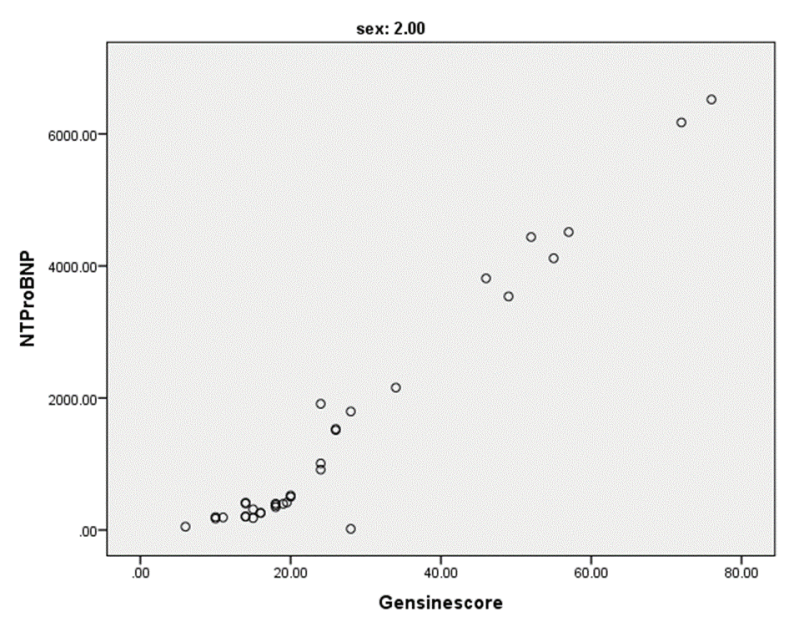

Figure 3: Correlation between Serum Levels of NT-proBNP and Gensini Scores in Females

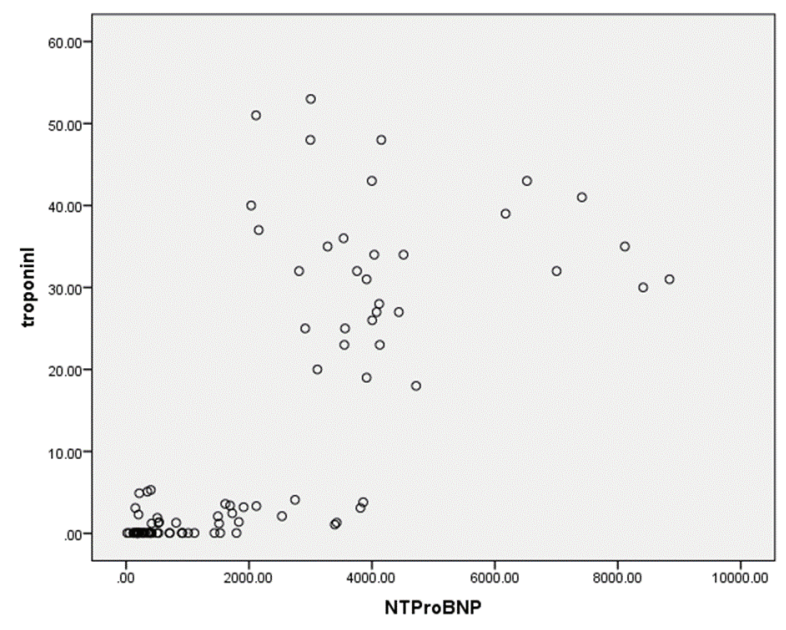

Figure 4: Correlation between Troponin I and NT-proBNP Levels

Besides, while there was no significant difference in Gensini scores of smoker and non-smoker patients $(\mathrm{P}=0.08)$; smoker patients had higher NT-proBNP levels $(\mathrm{P}=0.047)$.

There was no correlation in Gensini scores and NT-proBNP levels with laboratory results of the patients (Tables 3 and 4).

\section{DISCUSSION}

In this study, we recruited patients with ACS and studied the correlation between their serum levels of NT-proBNP and Gensini scores. We found that the Spearman's coefficient of the correlation between serum levels of NT-proBNP and Gensini scores in our patients with ACS was 0.953 ( $\mathrm{P}<$ 0.001 ), which showed a powerful direct correlation between 


\begin{tabular}{|lcc|}
\hline \multicolumn{2}{|l|}{ Table 3: Correlation between Gensini Score and Laboratory Results } & \\
Variable & Correlation coefficient & P value \\
Blood sugar & 0.1 & 0.73 \\
HDL & -0.04 & 0.82 \\
Triglyceride & 0.003 & 0.34 \\
LDL & 0.086 & 0.76 \\
Cholesterol & 0.058 & 0.85 \\
\hline
\end{tabular}

HDL: High-density lipoprotein; LDL: Low-density lipoprotein

\begin{tabular}{|lcc|}
\hline \multicolumn{2}{|l|}{ Table 4: Correlation between Serum Level of NT-proBNP and Laboratory Results } & P value \\
Variable & Correlation coefficient & 0.375 \\
Blood sugar & 0.90 & 0.839 \\
HDL & -0.021 & 0.893 \\
Triglyceride & -0.014 & 0.773 \\
LDL & 0.029 & 0.987 \\
Cholesterol & -0.002 & \\
\hline
\end{tabular}

HDL: High-density lipoprotein; LDL: Low-density lipoprotein

the two variables. The correlation was also statistically significant in both genders and in three subgroups of patients with UA, STEMI and NSTEMI. NT-proBNP was first used as an indicator of heart failure and stress on myocardial tissue; but it seems that it can also be considered as a valuable biomarker for predicting the severity of $\mathrm{CAD}$ and therefore the severity of myocardial ischemia.

The results of our study about the correlation between NT-proBNP and Gensini score are consistent with previous reports. Wei and colleagues reported that NT-proBNP levels were found to go higher with the severity of myocardial ischemia in patients with UA [26]. In a study on patients with NSTEMI, the NT-proBNP levels progressively increased with the severity of $\mathrm{CAD}$, and increased levels of NT-proB$\mathrm{NP}$ independently predicted the presence of more complex coronary lesions [27]. Sahin Arslan and colleagues reported that plasma levels of $\mathrm{BNP}$ were higher in stable $\mathrm{CAD}$ patients with coronary artery stenosis of more than 50\% compared to those with less stenosis; also, the level of increase in plasma BNP concentration was positively correlated with the extent of lesion on coronary angiography [16]. Some other studies have also found that the NT-proBNP level has been correlated with the severity of coronary artery stenosis and Gensini score and suggested that the NT-proBNP level can be used as a predictor of angiographic results [10, 20, 28].

Despite the significant correlation between NT-proBNP levels and Gensini scores in our patients, the NT-proBNP levels were not significantly different in patients with SVD, 2VD and $3 \mathrm{VD}(\mathrm{P}=0.257)$. Inconsistent with our results, some studies have reported that NT-proBNP levels were positively correlated with the number of coronary vessels involved [10, 16]. However, individuals enrolled in those studies were patients with stable CAD. We also did not find any correlation between LAD involvement and NT-proBNP level; but in a study on patients with stable CAD [16] and another study on patients with UA and NSTEMI [29], patients with LAD involvement had higher NT-proBNP levels. Moreover, the results of our study showed that there was a direct correlation between NT-proBNP and troponin I levels (correlation coefficient $=0.779)$ in patients with ACS.
In addition to previous reports on higher NT-proBNP levels in patients with heart failure, we found that NT-proBNP levels had a negative correlation with $\mathrm{EF}$ in patients with ACS, too (correlation coefficient $=-0.55 ; \mathrm{P}=0.001$ ). Some researchers have reported same results in patients with NSTEMI [27] and stable CAD [20].

Besides, while dyslipidemia and high blood sugar are risk factors of CAD; neither NT-proBNP levels nor Gensini scores were correlated with plasma levels of HDL, LDL, TG, cholesterol and blood sugar. Additionally, in contrast to Gensini score, smoker patients had higher NT-proBNP levels $(\mathrm{P}=$ $0.047)$.

To conclude, serum levels of NT-proBNP can be used as an important biomarker for risk stratification of patients with ACS by predicting the CAD severity, Gensini score and troponin I levels. Further studies with higher numbers of patients are necessary to confirm the results of the current study.

\section{ACKNOWLEDGMENTS}

This study was performed in the Cardiovascular Research Center of Shahid Beheshti University of Medical Sciences. We acknowledge the staff of this Center for their valuable cooperation.

\section{CONFLICTS OF INTEREST}

There is no conflict of interest for the authors.

\section{REFERENCES}

1. Levin ER, Gardner DG, Samson WK. Natriuretic peptides. N Engl J Med. 1998;339(5):321-8. DOI: 10.1056/NEJM199807303390507 PMID: 9682046

2. Yasue H, Yoshimura M, Sumida H, Kikuta K, Kugiyama K, Jougasaki M, et al. Localization and mechanism of secretion of B-type natriuretic peptide in comparison with those of A-type natriuretic peptide in normal subjects and patients with heart failure. Circulation. 1994;90(1):195203. DOI: 10.1161/01.CIR.90.1.195 PMID: 8025996

3. Munagala VK, Burnett JC, Jr., Redfield MM. The natriuretic peptides in cardiovascular medicine. Curr Probl Cardiol. 2004;29(12):707-69. DOI: $10.1016 /$ j.cpcardiol.2004.07.002 PMID: 15550914

4. Yeo KT, Lee HK, Wong KC, Foote RS. Can exercise-induced changes in 
B-type natriuretic peptides be used to detect cardiac ischemia? J Card Fail. 2005;11(5 Suppl):S59-64. DOI: 10.1016/j.cardfail.2005.04.021 PMID: 15948103

5. Ikeda T, Matsuda K, Itoh H, Shirakami G, Miyamoto Y, Yoshimasa T, et al. Plasma levels of brain and atrial natriuretic peptides elevate in proportion to left ventricular end-systolic wall stress in patients with aortic stenosis. Am Heart J. 1997;133(3):307-14. DOI: 10.1016/S00028703(97)70225-4 PMID: 9060799

6. Magga J, Marttila M, Mantymaa P, Vuolteenaho O, Ruskoaho $\mathrm{H}$. Brain natriuretic peptide in plasma, atria, and ventricles of vasopressin- and phenylephrine-infused conscious rats. Endocrinology. 1994;134(6):2505-15. DOI: 10.1210/endo.134.6.8194476 PMID: $\underline{8194476}$

7. Sabatine MS, Morrow DA, de Lemos JA, Omland T, Desai MY, Tanasijevic $M$, et al. Acute changes in circulating natriuretic peptide levels in relation to myocardial ischemia. J Am Coll Cardiol. 2004;44(10):198895. DOI: 10.1016/j.jacc.2004.07.057 PMID: 15542281

8. Foote RS, Pearlman JD, Siegel AH, Yeo KT. Detection of exercise-induced ischemia by changes in B-type natriuretic peptides. J Am Coll Cardiol. 2004;44(10):1980-7. DOI: 10.1016/j.jacc.2004.08.045 PMID: 15542280

9. Ndrepepa G, Braun S, Mehilli J, von Beckerath N, Vogt W, Schomig A, et al. Plasma levels of $\mathrm{N}$-terminal pro-brain natriuretic peptide in patients with coronary artery disease and relation to clinical presentation, angiographic severity, and left ventricular ejection fraction. Am J Cardiol. 2005;95(5):553-7. DOI: 10.1016/j.amjcard.2004.10.034 PMID. $\underline{15721090}$

10. Tello-Montoliu A, Marin F, Roldan V, Mainar L, Lopez MT, Sogorb F, et al. A multimarker risk stratification approach to non-ST elevation acute coronary syndrome: implications of troponin T, CRP, NT pro-BNP and fibrin D-dimer levels. J Intern Med. 2007;262(6):651-8. DOI: 10.1111/j.1365-2796.2007.01871.x PMID: 17986200

11. Mayr A, Mair J, Schocke M, Klug G, Pedarnig K, Haubner BJ, et al. Predictive value of NT-pro BNP after acute myocardial infarction: relation with acute and chronic infarct size and myocardial function. Int J Cardiol. 2011;147(1):118-23. DOI: 10.1016/j.ijcard.2009.09.537 PMID: 19896736

12. de Lemos JA, McGuire DK, Drazner MH. B-type natriuretic peptide in cardiovascular disease. Lancet. 2003;362(9380):316-22. DOI: 10.1016/S0140-6736(03)13976-1 PMID: 12892964

13. Grewal J, McKelvie RS, Persson H, Tait P, Carlsson J, Swedberg K, et al. Usefulness of $\mathrm{N}$-terminal pro-brain natriuretic Peptide and brain natriuretic peptide to predict cardiovascular outcomes in patients with heart failure and preserved left ventricular ejection fraction. Am J Cardiol. 2008;102(6):733-7. DOI: 10.1016/j.amjcard.2008.04.048 PMID: $\underline{18773998}$

14. Palazzuoli A, Gallotta M, Quatrini I, Nuti R. Natriuretic peptides (BNP and NT-proBNP): measurement and relevance in heart failure. Vasc Health Risk Manag. 2010;6:411-8. DOI: 10.2147/VHRM.S5789 PMID: 20539843

15. Sahinarslan A, Cengel A, Okyay K, Yazici HU, Elbey S, Cemri M, et al. $\mathrm{B}$-type natriuretic peptide and extent of lesion on coronary angiography in stable coronary artery disease. Coron Artery Dis. 2005; 16(4):225-9. DOI: 10.1097/00019501-200506000-00003 PMID: 15915074

16. Yesil M, Postaci N, Arikan E, Ceylan O, Bayata S, Koseoglu M. Can we predict the severity of coronary artery disease in patients with stable angina using NT-ProBNP? Anadolu Kardiyol Derg. 2006;6(3):235-8. PMID: 16943107

17. Shahabi V, Moazenzadeh M, Azimzadeh BS, Nasri H, Afshar RM, Sha- hesmaili A, et al. Relationship between serum $\mathrm{N}$-terminal Pro Brain $\mathrm{Na}$ triuretic Peptide (NT-Pro BNP) level and the severity of coronary artery involvements. J Res Med Sci. 2011;16(2):143-8. PMID: 22091223

18. Sakai H, Tsutamoto T, Ishikawa C, Tanaka T, Fujii M, Yamamoto T, et al. Direct comparison of brain natriuretic peptide (BNP) and N-terminal pro-BNP secretion and extent of coronary artery stenosis in patients with stable coronary artery disease. Circ J. 2007;71(4):499-505. DOI 10.1253/circj.71.499 PMID: 17384449

19. Ollivier JP, Revel F. [Brain natriuretic peptide in acute coronary syndromes: utility of NT-pro BNP assay]. Bull Acad Natl Med. 2004;188(9):1529-38; discussion 38-40. PMID: 15997622

20. Kleczynski P, Legutko J, Rakowski T, Dziewierz A, Siudak Z, Zdzienicka J, et al. Predictive utility of NT-pro BNP for infarct size and left ventricle function after acute myocardial infarction in long-term follow-up Dis Markers. 2013;34(3):199-204. DOI: 10.3233/DMA-120955 PMID: 23334649

21. Omland T, Persson A, Ng L, O’Brien R, Karlsson T, Herlitz J, et al. $\mathrm{N}$-terminal pro-B-type natriuretic peptide and long-term mortality in acute coronary syndromes. Circulation. 2002;106(23):2913-8. DOI: 10.1161/01.CIR.0000041661.63285.AE PMID: 12460871

22. Marz W, Tiran B, Seelhorst U, Wellnitz B, Bauersachs J, Winkelmann $\mathrm{BR}$, et al. $\mathrm{N}$-terminal pro-B-type natriuretic peptide predicts total and cardiovascular mortality in individuals with or without stable coronary artery disease: the Ludwigshafen Risk and Cardiovascular Health Study. Clin Chem. 2007;53(6):1075-83. DOI: 10.1373/ clinchem.2006.075929 PMID: 17446333

23. Pfister R, Tan D, Thekkanal J, Hellmich M, Schneider CA. NT-pro-BNP is associated with long-term outcome in a heterogeneous sample of cardiac inpatients. Eur J Intern Med. 2007;18(3):215-20. DOI: 10.1016/j. ejim.2006.11.007 PMID: 17449394

24. Gensini GG. A more meaningful scoring system for determining the severity of coronary heart disease. Am J Cardiol. 1983;51(3):606. DOI: 10.1016/S0002-9149(83)80105-2 PMID: 6823874

25. Peppes V, Rammos G, Manios E, Koroboki E, Rokas S, Zakopoulos N. Correlation between myocardial enzyme serum levels and markers of inflammation with severity of coronary artery disease and Gensini score: a hospital-based, prospective study in Greek patients. Clin Interv Aging. 2008;3(4):699-710. PMID: 19281062

26. Wei G, Ningfu W, Xianhua Y, Liang Z, Jianmin Y, Guoxin T, et al. $\mathrm{N}$-terminal pro-B-type natriuretic peptide is associated with severity of the coronary lesions in unstable angina patients with preserved left ventricular function. J Interv Cardiol. 2012;25(2):126-31. DOI: 10.1111/j.1540-8183.2011.00697.x PMID: 22150844

27. Navarro Estrada JL, Rubinstein F, Bahit MC, Rolandi F, Perez de Arenaza D, Gabay JM, et al. NT-probrain natriuretic peptide predicts complexity and severity of the coronary lesions in patients with non-ST-elevation acute coronary syndromes. Am Heart J. 2006;151(5):1093 e1-7. DOI: $10.1016 /$ j.ahj.2005.12.020 PMID: 16644341

28. Kragelund C, Gronning B, Omland T, Kober L, Strande S, Steffensen R, et al. Is N-terminal pro B-type natriuretic peptide (NT-proBNP) a useful screening test for angiographic findings in patients with stable coronary disease? Am Heart J. 2006;151(3):712 e1- e7. DOI: 10.1016/j. ahj.2005.12.009 PMID: 16504637

29. Sadanandan S, Cannon CP, Chekuri K, Murphy SA, Dibattiste PM, Morrow DA, et al. Association of elevated B-type natriuretic peptide levels with angiographic findings among patients with unstable an gina and non-ST-segment elevation myocardial infarction. J Am Coll Cardiol. 2004;44(3):564-8. DOI: 10.1016/i.jacc.2004.03.072 PMID: $\underline{15358021}$ 